\title{
SISTEM PENCARIAN LOKASI BENGKEL MOBIL RESMI MENGGUNAKAN TEKNIK PENGOLAHAN SUARA DAN PEMROSESAN BAHASA ALAMI
}

\author{
A Ferico Octaviansyah'), Dedi Darwis'), Ade Surahman ${ }^{3)}$ \\ ${ }^{1,2,3}$ Fakultas Teknik dan Ilmu Komputer, Universitas Teknokrat Indonesia \\ 1,2,3 Jalan ZA No 9-11 Labuhan Ratu Bandar Lampung \\ Email: ${ }^{1}$ fericopasaribu@teknokrat.ac.id, ${ }^{2}$ darwisdedi@teknokrat.ac.id, ${ }^{3}$ adesurahman@teknokrat.ac.id
}

\begin{abstract}
Abstrak
Banyaknya jumlah bengkel resmi mobil yang tersebar di wilayah Bandar Lampung, terkadang masih membuat bingung pengguna dalam menemukan bengkel mobil mereka. Hal ini dikarenakan lokasi-lokasi bengkel mobil yang tercantum pada buku panduan hanya mencantumkan nama bengkel dan alamatnya saja. Permasalahannya adalah tidak semua orang mengetahui nama bengkel resmi dan alamat yang tercantum pada buku panduan. Salah satu cara untuk memberikan kemudahan pengguna mencari lokasi bengkel mobil resmi adalah dengan menggunakan teknik visualisasi peta, pengolahan suara dan pemrosesan bahasa alami menggunakan smartphone Android. Penelitian ini membahas bagaimana menerapkan teknik visualisasi peta dengan Google Maps, pengolahan suara dengan Speech Recognition dan Text to Speech serta pemrosesan bahasa alami yang akan dikombinasikan pada aplikasi. Hasil dari penelitian ini diharapkan dapat menjadi aplikasi yang dapat membantu para pengguna dalam mencari rute terdekat dalam mencari bengkel resmi mobil dengan bantuan Speech Recognition dan Text to Speech berupa aplikasi yang dapat mengolah keluaran suara dari pengguna menjadi bentuk teks. Berdasarkan hasil pengujian aplikasi ini memiliki tingkat akurasi sebesar 70\% dalam menemukan lokasi sesuai dengan yang diucapkan oleh pengguna.
\end{abstract}

Kata Kunci: NLP, Google Maps, Speech Recognation.

\section{Latar Belakang}

\section{Pendahuluan}

Semakin pesatnya perkembangan dunia otomotif di masyarakat yang terlihat dari banyaknya kendaraan bermotor yang beredar terutama mobil sehingga mendorong pihak produsen mobil untuk terus selalu mengembangkan jumlah bengkel resmi. Hal ini dimaksudkan untuk memudahkan para pengguna memperbaiki mobilnya ketika mengalami kerusakan. Banyaknya jumlah bengkel resmi mobil yang tersebar di wilayah kota Bandar Lampung, terkadang masih membuat bingung pengguna dalam menemukan bengkel mobil mereka. Hal ini dikarenakan lokasi-lokasi bengkel resmi mobil yang tercantum pada buku panduan hanya mencantumkan nama bengkel dan alamatnya saja.
Permasalahannya adalah tidak semua orang mengetahui nama bengkel resmi dan alamat yang tercantum pada buku panduan.

Salah satu cara untuk memberikan kemudahan pengguna mencari lokasi bengkel resmi mobil adalah dengan menggunakan teknik visualisasi lokasi dengan peta. Salah satu teknik visualisasi peta yang dapat digunakan adalah dengan Google Maps. Google Maps adalah sebuah jasa peta global virtual gratis dan online yang disediakan oleh Google dan dapat ditemukan di http://maps.google.com. Google Maps memberikan layanan untuk menunjukkan jalan-jalan yang ada di seluruh dunia [1]. Google Maps API adalah fungsi fungsi pemrograman yang disediakan oleh Google Maps agar Google Maps bisa diintegrasikan ke dalam Web atau Smartphone. Dengan penggunaan Google Maps API proses pencarian lokasi melalui peta atau dalam mengklasifikasikan wilayah akan menjadi lebih mudah dan cepat [2].

Speech Recognition adalah proses untuk mengenali suara seseorang dari sebuah frasa yang diucapkan. Dengan teknik ini pengguna dapat dengan mudah melakukan sebuah pencarian dengan menggunakan perintah suara [3]. Text to Speech adalah sistem konversi perubahan sebuah teks menjadi sinyal suara dan lebih dikenal dengan sebutan TTS (Text to Speech). Dengan adanya fasilitas Text to Speech pada aplikasi ini akan lebih membantu seseorang dalam menunjukan arah karena dapat memberikan perintah langsung kepada penggunanya berupa suara [3].

Pemrosesan bahasa alami (Natural Language Processing) merupakan salah satu aplikasi Artificial Intelligence (AI) yang dikembangkan agar komputer mengerti dan memahami bahasa alami yang diberikan dan memberi respon hasil pengolahan sesuai yang diinginkan. Natural Language Processing biasanya disingkat dengan NLP, mencoba membuat komputer mampu memahami suatu perintah yang dituliskan dalam bentuk bahasa sehari-hari dan diharapkan komputer juga merespon dalam bahasa yang mirip dengan bahasa natural [4].

Penelitian ini bertujuan untuk merancang dan menerapkan sebuah aplikasi yang mampu memberikan visualisasi peta menggunakan Google Maps versi 2 serta membuat aplikasi pencarian lokasi bengkel mobil resmi yang dapat mengintegrasikan Speech Recognition, Text to Speech dan Pemrosesan Bahasa Alami. Hasil dari 
penelitian ini diharapkan dapat membantu pengguna dalam mencari lokasi bengkel mobil resmi di wilayah Bandar Lampung dalam bentuk visualisasi peta Google Maps dengan mengintegrasikan Speech Recognition, Text to Speech dan Pemrosesan Bahasa Alami untuk memudahkan pengguna berkomunikasi dengan sistem dalam mencari lokasi bengkel mobil resmi.

\section{Metode}

\section{Rancangan Penelitian}

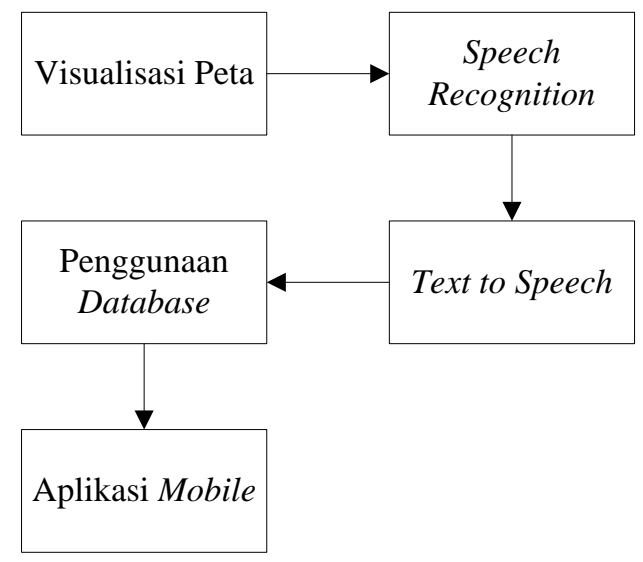

Gambar 1. Rancangan Penelitian

Rancangan penelitian tentang pencarian lokasi bengkel mobil resmi menggunakan teknik pengolahan suara dan pemrosesan bahasa alami pada Gambar 1 yaitu meliputi :

1. Visualisasi peta lokasi bengkel mobil resmi menggunakan Google Maps yang sudah tersedia di smartphone Android.

2. Penggunaan visualisasi peta dengan Google Maps masih belum cukup karena pengguna perlu mengisi data lokasi bengkel mobil resmi yang ingin dicari, sehingga diperlukan teknik pengolahan suara yang bertujuan untuk menggantikan proses pengisian data dalam format teks menjadi suara. Teknik pengolahan suara yang digunakan yaitu Speech Recognition dan Text to Speech yang sudah tersedia pada perangkat smartphone Android dalam bentuk Google Voice.

3. Teknik pengolahan suara masih memiliki keterbatasan dalam mengolah suara yang dikeluarkan oleh pengguna, karena pengguna harus mengeluarkan suara yang sama dengan alamat dari bengkel mobil resmi untuk mendapatkan hasil visualisasi peta yang sesuai. Dukungan database dan teknik pemrosesan bahasa alami diperlukan untuk lebih memudahkan pengguna dalam mencari lokasi bengkel mobil resmi, sehingga pengguna cukup menyebutkan nama produsen mobil untuk mencari lokasi bengkel mobil resmi. Selain itu, dengan teknik pengolahan suara pengguna dapat bereksperimen dalam mengeluarkan suara untuk mencari lokasi bengkel mobil resmi.
4. Pemanfaatan pencarian lokasi bengkel mobil ini hanya digunakan untuk pengguna yang ingin mencari lokasi bengkel mobil resmi.

\section{Jenis Data}

Data dalam penelitian ini menggunakan berbagai macam data khususnya data kualitatif. Data kualitatif ini berupa suara yang dikeluarkan oleh pengguna. Selain itu data kualitatif lainnya adalah teks, dimana teks ini dihasilkan dari suara yang dikeluarkan oleh pengguna untuk selanjutnya diolah menggunakan pemrosesan bahasa alami. Dalam penelitian ini juga digunakan data kuantitatif yang berkaitan dengan visualisasi peta Google Maps. Visualisasi peta Google Maps dihasilkan setelah melalui pemrosesan bahasa alami, dimana visualisasi peta Google Maps menggunakan titik koordinat (x,y) untuk mencari lokasi bengkel mobil resmi.

\section{Tahapan Penelitian}

Tahapan-tahapan penelitian dapat dideskripsikan pada Gambar 2.

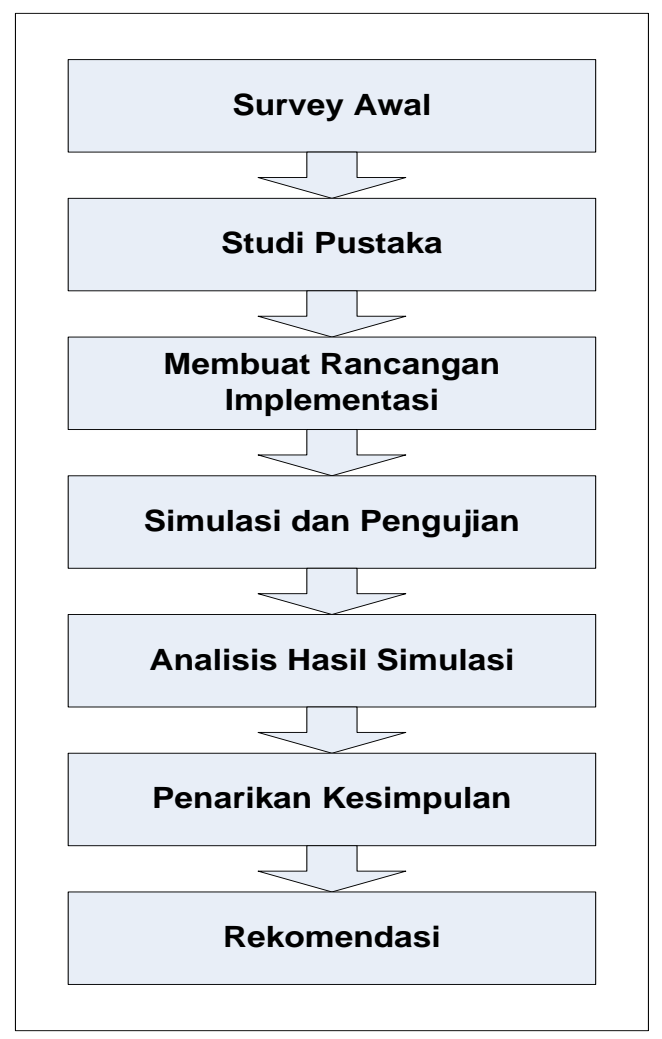

Gambar 2. Tahapan Penelitian

Penjelasan pada Gambar 2:

1) Melakukan Survey Awal Langkah ini bertujuan untuk mengetahui lokasi bengkel mobil resmi. Survey awal ini merupakan salah satu metode pengumpulan data yang dalam penelitian ini dilakukan dengan teknik observasi.

2) Melakukan Studi Pustaka

Penelitian ini dimulai dengan melakukan studi pustaka yang berkaitan dengan konsep pengolahan suara menggunakan Speech Recognition dan Text to 
Speech, konsep pemrosesan bahasa alami, algoritma Parsing dan Stemming, konsep Global Positioning System (GPS), konsep visualisasi peta dengan Google Maps dan konsep pemrograman.

3) Membuat Rancangan Implementasi

Langkah selanjutnya adalah membuat rancangan yang berkaitan dengan penerapan teknik pengolahan suara dan pemrosesan bahasa alami untuk mencari lokasi bengkel mobil resmi. Adapun rancangan yang dibuat adalah berupa flowchart alur sistem, flowchart pengolahan suara, pemrosesan bahasa alami dan visualisasi peta, use case yang menggambarkan bagaimana sistem akan dijalankan oleh para aktor atau user dan rancangan basis data yang terkait dengan penyimpanan data lokasi bengkel mobil resmi.

4) Simulasi dan Pengujian

Pada tahap ini peneliti melakukan simulasi dan pengujian yaitu dengan memasukan data-data yang terkait dengan lokasi bengkel mobil resmi kemudian data-data tersebut diolah menggunakan aplikasi web, selanjutanya data-data tersebut digunakan oleh pengguna untuk mencari lokasi bengkel mobil resmi menggunakan aplikasi Android.

Berikut ini adalah kondisi yang akan disimulasikan dan diujikan oleh peneliti :

a. Mengolah Data Lokasi Bengkel Mobil Resmi Pada tahap ini data-data yang terkait dengan lokasi bengkel mobil resmi diolah oleh administrator. Data yang diolah berupa nama produsen mobil, nama alamat bengkel mobil resmi, titik koordinat (x,y) lokasi bengkel mobil resmi yang didapat dari Google Maps.

b. Mengolah Keluaran Suara

Setelah data-data yang terkait dengan lokasi bengkel mobil resmi dimasukkan, pengguna menggunakan aplikasi berbasis Android untuk mencari lokasi bengkel mobil resmi. Pengguna mencari lokasi bengkel mobil resmi dengan cara mengeluarkan suara dalam format bahasa Indonesia.

c. Konversi Keluaran Suara

Tahap ini adalah proses konversi setiap keluaran suara pengguna menjadi bentuk teks menggunakan Google Voice.

d. Menyusun Aturan

Keluaran suara pengguna yang telah diolah menjadi bentuk teks, selanjutnya diolah untuk menyusun aturan. Berikut ini aturan yang digunakan :

$\checkmark$ Kata Kerja / Kata Tanya (KK / KT)

Terdiri atas "tampil","cari", "lihat".

$\checkmark$ Kata Benda / Field (KB / F)

Terdiri dari kata yang mewakili nama tabel, yaitu "bengkel".

$\checkmark$ Objek (O)

Terdiri dari kata yang mewakili isi data pada tabel, yaitu "nama produsen mobil"

$\checkmark \quad$ Pelengkap (P)
Terdiri dari kata yang melengkapi kalimat, yaitu "tolong", "lokasi", "tempat".

$\checkmark$ Kalimat

Terdiri dari kata-kata hasil penggabungan kata kerja / kata tanya, kata benda dan pelengkap. Pola yang dapat digunakan dalam menyusun kalimat yaitu :

- Kalimat $=\mathrm{KK} / \mathrm{KT}+\mathrm{P}+\mathrm{KB} / \mathrm{F}+\mathrm{O}$ Contoh : "cari lokasi bengkel Honda".

- Kalimat $=\mathrm{P}+\mathrm{KK} / \mathrm{KT}+\mathrm{P}+\mathrm{KB} / \mathrm{F}$ $+\mathrm{O}$

Contoh : "tolong carikan lokasi bengkel Honda".

e. Pemrosesan Bahasa Alami

Tahap ini adalah proses translate aturan produksi menjadi perintah SQL. Pada tahap ini juga dilakukan pengujian terhadap aturan produksi yang sudah dibuat menggunakan algoritma Parsing dan Stemming. Aturan produksi yang sudah menjadi bentuk kalimat, selanjutnya diolah dengan cara berikut :

$\checkmark$ Pemenggalan Kata

Kalimat "tolong carikan lokasi bengkel

Honda" dipenggal menjadi :

- Tolong

- Carikan

- Lokasi

- Bengkel

- Honda

$\checkmark$ Pemilihan Kata

Hasil pemenggalan kata dipilah menjadi dua bagian, yaitu kata bermakna atau kata tidak bermakna.

- Tolong : kata tidak bermakna

- Carikan : kata bermakna

- Lokasi : kata tidak bermakna

- Bengkel : kata bermakna

- Honda : kata bermakna

$\checkmark$ Pencarian Kata Dasar/Root Word

Tahapan ini adalah mencari kata dasar/root word dari kata yang memiliki imbuhan awalan (prefix) atau akhiran (suffix). Pada kasus ini kata yang mengandung imbuhan yaitu "carikan". Selanjutnya, kata tersebut dihilangkan imbuhannya menjadi "cari".

$\checkmark$ Penyesuaian Kata

Kalimat yang sudah dipilah menjadi kata bermakna atau tidak bermakna, selanjutnya dilakukan penyesuaian dengan cara menghilangkan kata yang tidak bermakna. Kata yang bermakan disesuaikan berdasarkan aturan produksi yang digunakan

$\begin{array}{ll}\text { - Cari } & \text { : KK / KT } \\ \text { - Bengkel } & : \text { KB / F } \\ \text { - Honda } & : \mathrm{O}\end{array}$


$\checkmark \quad$ Penentuan Pola Kalimat

Setelah proses penyesuaian kata dilakukan, tahap selanjutnya adalah menentukan pola kalimat.
- KK/KT : "select"
- $\mathrm{KB} / \mathrm{F} \quad$ : "bengkel"
- O : "nama produsen mobil"

$\checkmark \quad$ Penerjemahan Pola Kalimat

Tahap ini adalah proses menerjemahkan pola kalimat ke dalam bentuk Query berdasarkan hasil penentuan pola kalimat, sehingga didapatkan hasil "SELECT * FROM bengkel WHERE nama_produsen = 'Honda'".

f. Visualisasi Peta

Setelah tahap pemrosesan bahasa alami dilakukan, langkah terakhir adalah menampikan visualisasi peta. Visualisasi didapat dengan cara mengambil titik koordinat $(\mathrm{x}, \mathrm{y})$ berdasarkan hasil penerjemahan pola kalimat pada tahap pemrosesan bahasa alami. Jika pencarian lokasi bengkel mobil resmi ditemukan, maka aplikasi akan memberikan informasi kepada pengguna dalam bentuk suara terkait waktu tempuh dan jarak tempuh untuk sampai ke lokasi bengkel mobil resmi.

5) Analisis Hasil Simulasi

Melakukan pengamatan evaluasi dari hasil simulasi dan pengujian yang sudah dilakukan.

6) Penarikan Kesimpulan

Penarikan kesimpulan ini bertujuan untuk menjelaskan kesesuain hasil rancangan untuk diterapkan pada aplikasi pencarian lokasi bengkel mobil resmi.

7) Rekomendasi

Tahapan ini bertujuan untuk mengusulkan rancangan implementasi pencarian lokasi bengkel mobil resmi untuk diterapkan dan digunakan oleh pengguna yang ingin mencari lokasi bengkel mobil resmi.

\section{Hasil dan Pembahasan}

\section{Analisis Kebutuhan Sistem (Fungsional)}

Sistem yang dikembangkan harus mempunyai kebutuhan fungsional sebagai berikut :

1) Sistem harus dapat mengelola data produsen mobil, data nama bengkel mobil resmi dan data lokasi bengkel mobil resmi.

2) Sistem harus dapat memberikan informasi kepada pengguna dalam bentuk teks dan suara ketika perangkat GPS smartphone Android atau koneksi internet pengguna bermasalah.

3) Sistem harus dapat memudahkan pengguna dalam mencari lokasi bengkel mobil resmi, baik dari segi user interface maupun kemudahan dalam menggunakan aplikasi.
4) Sistem harus dapat merespon masukan suara pengguna dalam mencari lokasi bengkel mobil resmi.

5) Sistem harus dapat memberikan informasi kepada pengguna dalam bentuk teks dan suara ketika pencarian lokasi bengkel mobil resmi tidak ditemukan.

6) Sistem harus dapat menginformasikan kepada pengguna tentang prediksi jarak dan waktu tempuh untuk sampai ke lokasi bengkel mobil resmi dalam bentuk teks dan suara ketika lokasi bengkel mobil resmi ditemukan.

\section{Analisis Kebutuhan Sistem (Non Fungsional)}

Kebutuhan non fungsional pada sistem ini meliputi :

1) Kebutuhan Operasional

a) Kebutuhan Hardware

$\checkmark$ Koneksi internet

$\checkmark$ Koneksi GPS (Global Positioning System)

$\checkmark$ Perangkat PC (Personal Computer) lengkap

$\checkmark$ Smartphone Android

b) Kebutuhan Software

$\checkmark$ Sistem Operasi Windows 8.1.64 bit

$\checkmark$ Sistem Operasi Android (minimal versi Honeycomb/API 11/ Android 3.0)

$\checkmark$ Web Server Apache

$\checkmark$ Database MySQL

$\checkmark$ Framework Code Igniter

$\checkmark$ Eclipse Juno

$\checkmark$ Notepad++

\section{Analisis Proses Bisnis}

Proses bisnis pada sistem diawali dengan pengisian data oleh admin melaui interface web. Data yang diisikan berupa data produsen mobil, data nama bengkel mobil resmi dan lokasi bengkel mobil resmi. Pada saat pengisian data lokasi bengkel mobil resmi, admin juga mengisi koordinat latitude (x) dan longitude (y) yang diambil dari Google Maps untuk memetakan lokasi bengkel mobil resmi. Proses berikutnya adalah pengguna mengakses aplikasi melalui smartphone Android yang sudah terkoneksi dengan internet dan GPS (Global Positioning System) untuk mencari lokasi bengkel mobil resmi. Pengguna cukup berkomunikasi dengan sistem menggunakan suara untuk menampilkan lokasi bengkel mobil resmi yang dicari pengguna.

Selanjutnya, sistem merespon masukan suara dari pengguna. Jika pencarian lokasi bengkel mobil resmi tidak ditemukan, maka sistem akan memberikan informasi kepada pengguna dalam bentuk teks dan suara bahwa pencarian lokasi bengkel mobil tidak ditemukan. Jika pencarian lokasi bengkel mobil resmi ditemukan, maka sistem akan memberikan respon dalam bentuk visualisasi peta. Selain bentuk visualisasi peta, sistem juga memberikan informasi kepada pengguna tentang prediksi jarak dan waktu tempuh untuk sampai ke lokasi bengkel mobil resmi.

\section{Rancangan Use Case Diagram}

Sebelum pengguna menggunakan aplikasi untuk melakukan pencarian lokasi bengkel mobil resmi, admin 
sistem melakukan pengisian data terkait yang terdiri dari data pengguna/admin, data provinsi, data kabupaten/kota, data produsen dan data bengkel. Data-data tersebut diisi oleh admin sistem menggunakan interface web. Selanjutnya, pengguna dapat melakukan pencarian lokasi bengkel mobil resmi menggunakan interface Android. Pengguna cukup menyebutkan nama bengkel, kemudian aplikasi mengolah masukan suara dari pengguna untuk ditampilkan dalam bentuk visualisasi peta dengan Google Maps seperti yang diilustrasikan pada Gambar 3.

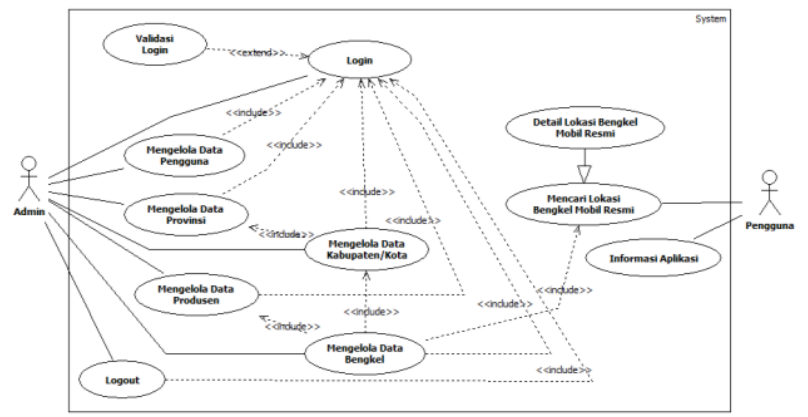

Gambar 3. Rancangan Use Case Diagram

\section{Flowchart Program Pengolahan Suara, Pemrosesan Bahasa Alami dan Visualisasi Peta}

Masukan suara dari pengguna diolah/diproses oleh sistem dengan cara melakukan konversi suara menjadi teks (Speech Recognition). Selanjutnya, data dalam bentuk teks tersebut diolah menggunakan pemrosesan bahasa alami untuk selanjutnya diuji menggunakan algoritma parsing. Proses parsing ini bertujuan untuk mengambil setiap kata dari teks/kalimat. Setelah melewati tahap parsing, sistem mengolah data hasil parsing dengan algoritma stemming. Proses stemming bertujuan untuk menghilangkan imbuhan (prefix dan suffix) yang terdapat pada setiap kata sehingga kata dasar/root word ditemukan. Selanjutnya, data hasil stemming diproses untuk ditampilkan dalam bentuk visualisasi peta (Google Maps). Detail data dari visualisasi peta selain ditampilkan dalam bentuk teks juga ditampilkan dalam bentuk suara. Suara yang dihasilkan, didapat dari teks hasil visualisasi peta yang dikonversikan menjadi bentuk suara (Text to Speech), seperti yang digambarkan melalui flowchart pada Gambar 4.

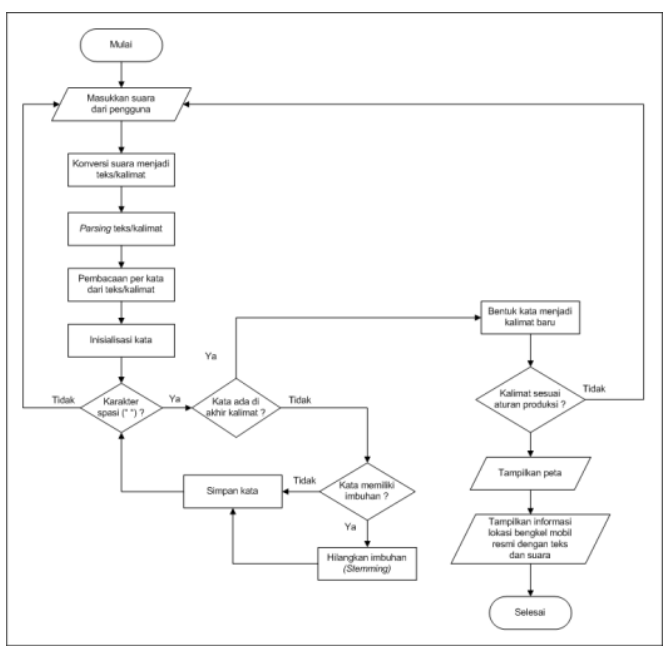

Gambar 4. Flowchart Program

\section{Tampilan Program Administrator}

Sesuai dengan rancangan use case pada Gambar 3, sistem ini dibagi menjadi dua user yaitu Admin dan Pengguna. Admin bertugas untuk mengisi data-data bengkel resmi di wilayah Bandar Lampung beserta lokasinya. Contoh tampilan program untuk administrator dapat dilihat pada Gambat 5(a) dan Gambar 5(b).

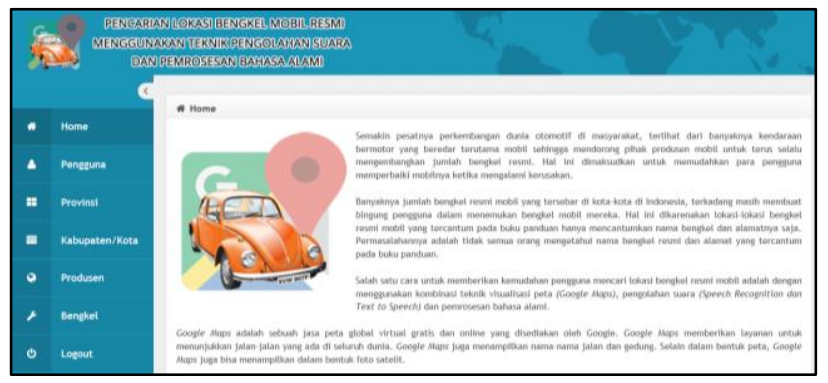

Gambar 5(a). Tampilan Program Utama Admin

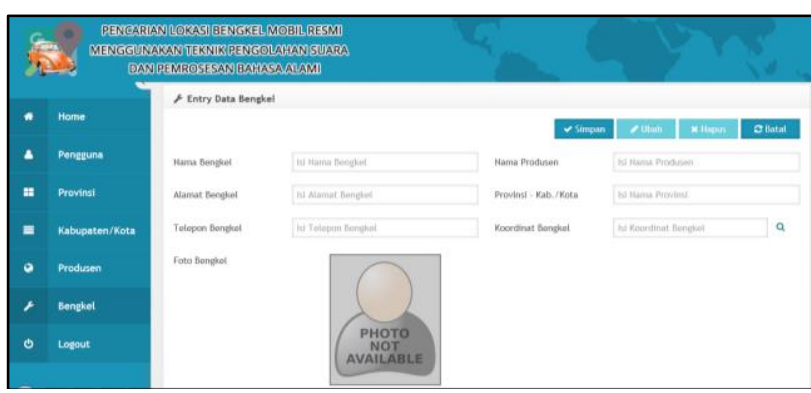

Gambar 5(b). Tampilan Program Entry Data Bengkel

\section{Tampilan Program Pengguna (User)}

Tampilan program ini berfungsi untuk mencari lokasi bengkel resmi di wilayah Bandar Lampung dengan cara user harus mengucapkan nama bengkel yang dituju, selanjutnya sistem akan merespon sesuai dengan nama bengkel yang ditemukan dengan catatan bengkel tersebut sudah terdaftar di dalam database yang diinput oleh admin. Contoh Tampilan program untuk pengguna dapat dilihat pada Gambar 6(a), Gambar 6(b), Gambar 6(c), dan Gambar 6(d). 


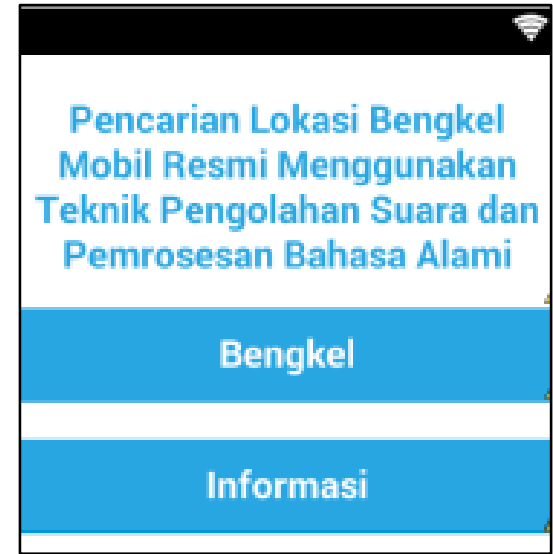

Gambar 6(a). Tampilan Menu Utama User

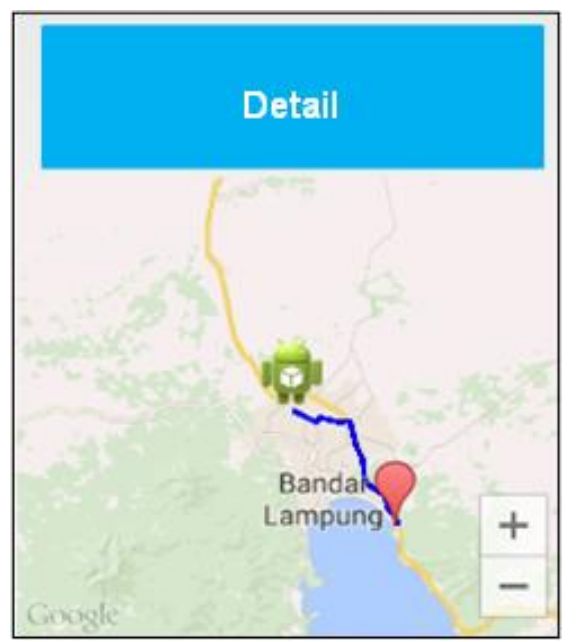

Gambar 6(b). Tampilan Pencarian Lokasi Menggunakan Suara

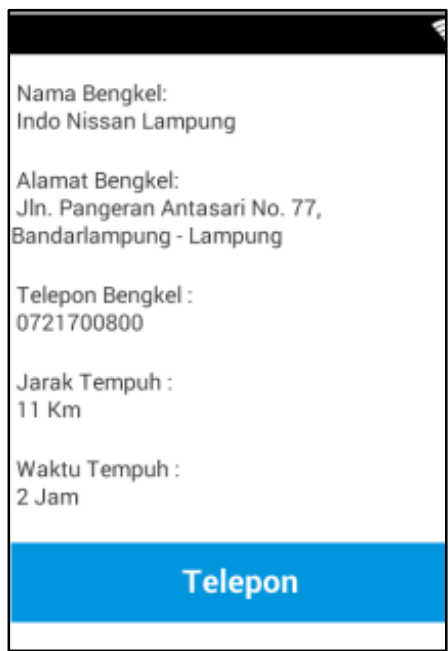

Gambar 6(c). Tampilan Hasil Pencarian Lokasi Bengkel

\section{Informasi}

Kata Kunci Tidak Sesuai.

Gunakan Kata Kunci

"cari","tampil" atau "lihat"

\section{Tutup}

Gambar 6(d). Tampilan Hasil Pencarian Lokasi Tidak Ditemukan

\section{Hasil Pengujian Aplikasi}

Pengujian dilakukan dengan melibatkan lima responden sebagai sampel, responden diminta untuk menggunakan aplikasi sesuai dengan aturan yang berlaku pada aplikasi. Setiap responden diberikan dua kali untuk melakukan simulasi.

Tabel 1. Hasil Pengujian Aplikasi

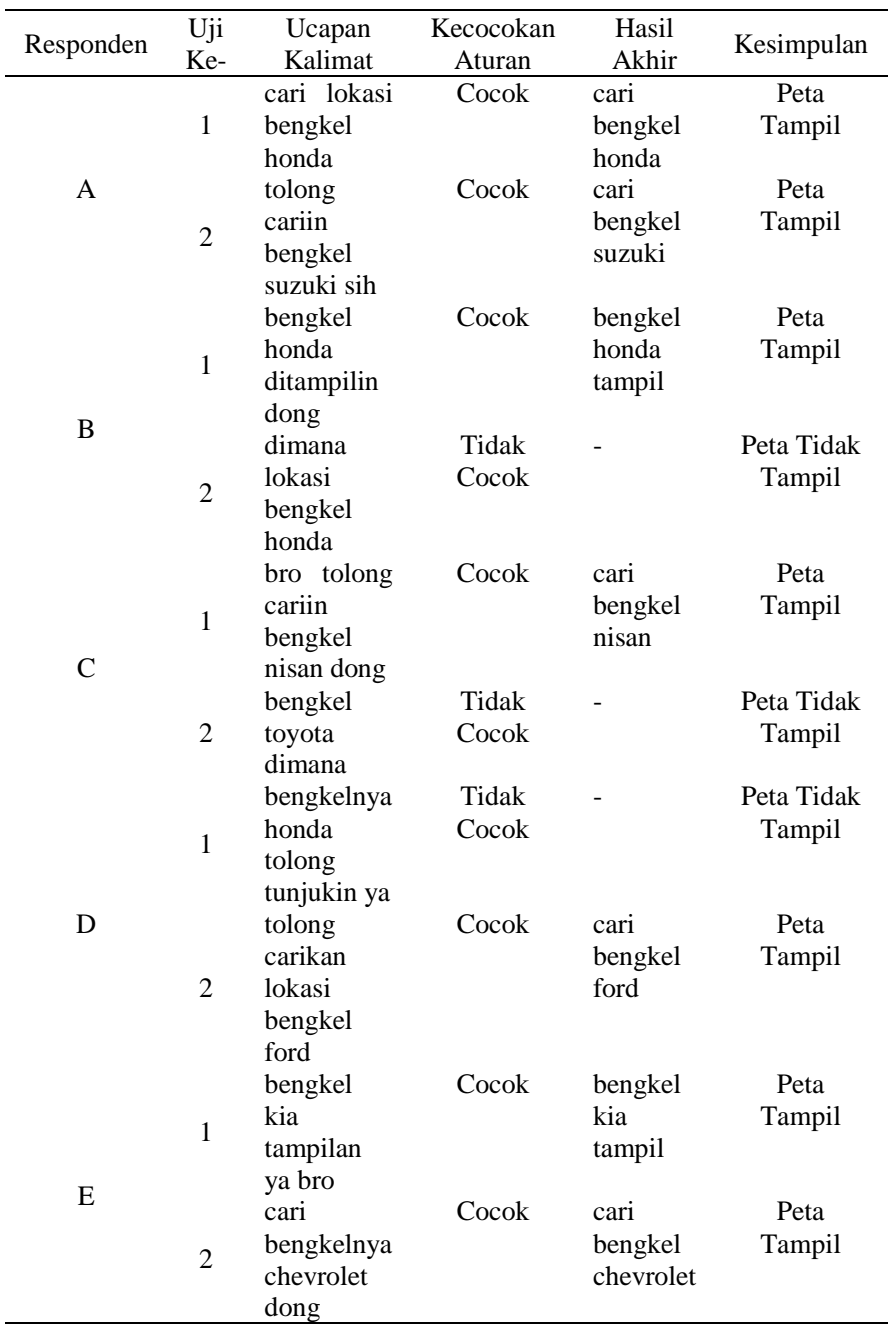

Berdasarkan hasil pengujian pada Tabel 1 maka didapatkan grafik persentase seperti pada Gambar 7. 


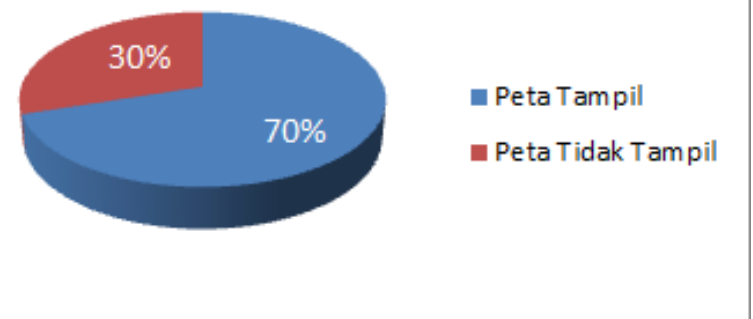

Gambar 7. Grafik Persentase Hasil Pengujian

Berdasarkan simulasi dan pengujian yang sudah dilakukan maka dapat dilihat bahwa proses pencarian lokasi bengkel mobil resmi di wilayah Bandar Lampung dapat dilakukan menggunakan kombinasi pengolahan suara, pemrosesan bahasa alami dan visualisasi peta. Hal ini dapat dilihat dari bagaimana masukan suara dari pengguna dapat diterjemahkan menjadi bentuk visualisasi peta. Hasil dari pengujian juga menunjukkan bahwa pengguna dapat dengan bebas memasukkan suara pada sistem dengan syarat masukkan suara dari pengguna cocok dengan aturan produksi yaitu "cari","tampil" dan "lihat". Adapun kegagalan pada saat menampilkan visualisasi peta, disebabkan karena masukkan suara dari pengguna tidak sesuai dengan aturan.

\section{Kesimpulan}

Visualisasi peta dalam mencari lokasi bengkel mobil resmi dapat diterapkan menggunakan Google Maps, namun pemanfaatan Google Maps perlu dikombinasikan juga dengan teknik pengolahan suara dan pemrosesan bahasa alami agar pengguna dapat mencari lokasi bengkel mobil resmi hanya dengan masukan berupa suara. Masukan suara dari pengguna tersebut yang selanjutnya dikonversikan dalam bentuk visualisasi peta. Berdasarkan hasil simulasi dan pengujian yang dilakukan terhadap responden, didapatkan persentase keberhasilan sistem sebesar 70\%. Kegagalan sebesar 30\% disebabkan masukan suara dari pengguna tidak sesuai dengan aturan.

\section{Daftar Pustaka}

[1] Minarni, "Sistem Informasi Geografis Pariwisata Kota Padang Menggunakan Application Programming Interface (API) Google Maps Berbasis
Web", Institut Teknologi Padang, TEKNOIF, Vol. 3 No 1. Hal. 31-37, 2013.

[2] D. Darwis, "Aplikasi Kelayakan Lahan Tanam Singkong Berdasarkan Hasil Panen Berbasis Mobile", Jurnal TEKNOINFO, Vol. 10, No.1, Hal 15. 2016.

[3] J. Dirmansyah, M.Z. Awaludin, D. Hermanto, "Rancang Bangun Aplikasi Penunjuk Arah Berbahasa Indonesia Berbasis Text to Speech dan Speech Recognition pada Perangkat Android", STMIK GI MDP, 2015.

[4] R.I. Borman, B. Priyopradono, "Implementasi Penerjemah Bahasa Isyarat Pada Bahasa Isyarat Indonesia (BISINDO) Dengan Metode Principal Component Analysis (PCA)", Jurnal Informatika: Jurnal Pengembangan IT, Vol.3 No.1. Hal. 103-108, 2018.

[5] S. Wibisono, "Aplikasi Pengolah Bahasa Alami untuk Query Basisdata Akademik dengan Format Data XML", Universitas Stikubank, DINAMIK, Vol. 18. No.1, 2013.

[6] P.M.M. Pramadewi, M.W.A. Kesiman, I.G.M. Darmawiguna, "Pengembangan Aplikasi Text to Speech untuk Bahasa Bali, Universitas Pendidikan Ganesha, JANAPATI, Vol. 2, No.3, 2013.

[7] M. Najib, D. Sunaryo, U.L. Yuhana, "Analisis dan Perancangan Aplikasi Penuntun Jalan dengan Perintah Suara Berbahasa Indonesia pada Perangkat Bergerak Berbasis Android", Institut Teknologi Sepuluh November, POMITS, Vol. 2, No.2, 2013.

[8] M.A. Anusuya, S.K. Katti, "Speech Recognition by Machine: A Review". Interational Journal of Computer Science and Information Security (IJCSIS), Vol. 6, No.3, 2009.

[9] Sutojo, Kecerdasan Buatan.,Andi, Yogyakarta, 2011.

[10] L. Agusta, "Perbandingan Algoritma Stemming Porter dengan Algoritma Nazief \& Adriani Untuk Stemming Dokumen Teks Bahasa Indonesia", Universitas Kristen Satya Wacana, Konferensi Nasional Sistem dan Informatika (KNS\&I), KNS\&I09-036, 2009. 